\title{
The hormone replacement therapy drug tibolone acts very similar to medroxyprogesterone acetate in an estrogen- and progesterone-responsive endometrial cancer cell line
}

\author{
P Hanifi-Moghaddam, B Sijmons, M C Ott ${ }^{4}$, W F J van IJcken², D Nowzari, E C M Kuhne, \\ P van der Spek ${ }^{3}$, H J Kloosterboer ${ }^{5}$, C W Burger ${ }^{1}$ and L J Blok \\ Departments of Reproduction and Development, ${ }^{1}$ Obstetrics and Gynecology, ${ }^{2}$ Center for Biomics, ${ }^{3}$ Bioinformatics, Erasmus University Medical Center, 3000 DR Rotterdam, \\ The Netherlands, ${ }^{4}$ OmniViz, Inc., Maynard, Massachusetts, USA and ${ }^{5}$ Research and Development Laboratories, N V Organon, 5340 BH Oss, The Netherlands \\ (Requests for offprints should be addressed to P Hanifi-Moghaddam; Email: p.hanifi_moghaddam @erasmusmc.nl)
}

\begin{abstract}
Tibolone, a steroidogenic compound with both estrogenic and progestagenic properties, is used as an alternative for estrogen or estrogen plus progesterone hormone therapy for the treatment of symptoms associated with menopause and osteoporosis. We have evaluated whether the effect of tibolone on a human endometrial cell line is similar to, or comparable with, the effect of estradiol $\left(E_{2}\right)$, medroxyprogesterone acetate (MPA) or $E_{2}+$ MPA treatment. Using stable transfection techniques, the estrogen receptor (ER) expressing human endometrial cancer cell line, ECC1, was altered to also express both progesterone receptors (PRs). These cells were then used to assess growth regulation and expression profiling (Affymetrix U133plus2) under the influence of $E_{2}(1 \mathrm{nM})$, MPA (1 nM), $E_{2}+$ MPA or tibolone (100 nM). Growth assessment and comparison of profiles indicate that tibolone behaves predominantly like MPA. Furthermore, regulation of prereplication complex genes, such as the minichromosome maintenance genes, could be involved in the observed strong inhibition of growth by tibolone as well as MPA. In addition, in total, 15 genes were found to be specific for tibolone treatment. These genes were predominantly involved in regulation of the cell cycle and differentiation.
\end{abstract}

Journal of Molecular Endocrinology (2006) 37, 405-413

\section{Introduction}

The results of the Million Women Study (Anderson et al. 2003, Beral et al. 2005) have raised concern regarding safety of estrogen or estrogen plus progesterone hormone replacement therapies (HRT). Therefore, there is a renewed interest in the evaluation of potential therapies that may be used as an alternative to estradiol $\left(\mathrm{E}_{2}\right)$ or $\mathrm{E}_{2}+\mathrm{MPA}$ hormone substitutions. Tibolone, a steroidogenic compound used for the treatment of symptoms associated with menopause and osteoporosis, could be a useful alternative to the HRT regimens like estrogen plus progestagen or estrogenonly treatment.

In the premenopausal endometrium, estrogens induce proliferation which is counteracted by the differentiative activities of progestagens (Markiewicz \& Gurpide 1990). For a hormone replacement therapy drug, it is important to display potent estrogenic activities for prevention of osteoporosis and climacteric complaints; however, for the endometrium, these estrogenic activities need to be balanced with appropriate progestagenic action. As indicated in literature (Kloosterboer 2001, de Gooyer et al. 2003), tibolone can be converted into estrogenic as well as progestagenic metabolites and for the endometrium, the progestagenic properties of tibolone seem to outweigh its estrogenic activities (de Gooyer et al. 2003). The reason for this can be twofold: first, tibolone may preferentially be converted into its progestagenic $\Delta^{4}$-isomer (Tang et al. 1993) and the second, tibolone has been described to induce sulfotransferase activity (Tseng \& Gurpide 1975) in the endometrium. Sulfotransferases are enzymes involved in the inactivation of endogenous estrogens and estrogenic compounds like tibolone's $3 \alpha-$

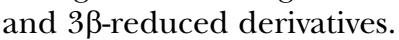

In order to investigate tibolone's estrogenic and progestagenic properties, in earlier work, we have used two separate cell lines: a solely estrogen-sensitive endometrial cancer cell line (ECC1) and a solely progesteronesensitive Ishikawa endometrial cell line. We have shown that the estrogenic activity of tibolone is potentially counterbalanced by the progestagenic metabolite of tibolone via differential regulation of similar cellular processes (Hanifi-Moghaddam et al. 2005). Because these experiments did not take into account the effects of estrogens or estrogen-like compounds on the progesterone receptor (PR) and effects of progestagens or progestagen-like compounds on the estrogen receptor (ER), we have set up a new study to evaluate the estrogenic 
and the progestagenic properties of tibolone in the same cell line expressing both PR and ER. Therefore, we have generated a progesterone- and estrogen-sensitive ECC1 cell line.

The central question in this study is whether the effect of tibolone on a human ECC1-PRAB72 is similar to, or comparable with, the effect of estrogen, progesterone, or a combination of both. In this paper, we analyze and compare the gene expression profiles reflecting the endometrial response to tibolone, $\mathrm{E}_{2}$, MPA, and a combination of both $\left(\mathrm{E}_{2}+\mathrm{MPA}\right)$. The results indicate that the addition of tibolone to these cells results in a potent progestagenic response and, interestingly, also in a tibolone-specific response.

\section{Materials and methods}

\section{Construction and culture conditions of ECC1 cell lines stably expressing hER $\alpha, \mathrm{hER} \beta, \mathrm{hPRA}$, and hPRB}

\section{Recombinant plasmids}

The hPR-cDNA cloned into the pSG5 expression vector was a generous gift from Dr E Milgrom (KremlinBicetre, Paris, France). This vector was used to create human progesterone receptor A (hPRA) and progesterone receptor B (hPRB) expression plasmids (Smid-Koopman et al. 2005).

\section{Cell culture and stable transfection}

ECC1 cells are derived from a well-differentiated human endometrial adenocarcinoma (Satyaswaroop et al. 1983) and were a generous gift from Dr B van den Burgh (Hubrecht laboratory, Utrecht, The Netherlands). The ECC1 cell line endogenously expresses high levels of hER $\alpha$ (comparable to in vivo endometrial levels, not shown) and low levels of hER $\beta$ (comparable to the situation in vivo) (Taylor \& Al-Azzawi 2000). The cells were maintained, transfected, and selected for as described by Smid-Koopman et al. (2005). The initial selection resulted in three potentially useful clones. One clone, ECC1PRAB72 was chosen for further characterization and used for the gene expression profiling experiments. All experiments were conducted with cells cultured for one whole passage in DMEM/F12 medium devoid of phenol red and supplemented with 5\% dextrancoated charcoal-treated fetal calf serum (DCC-FCS) before the experiments were started in the same medium. The hormonal concentrations used are indicated in the figure legends.

\section{Characterization of the ECC1-PRAB72 cells}

\section{Western immunoblotting}

The cells were cultured in the presence or absence of tibolone, $\mathrm{E}_{2}$, MPA, or $\mathrm{E}_{2}+\mathrm{MPA}$. The hormonal concentrations are indicated in the figure legends. The antibodies used were: mouse monoclonal antibody recognizing PRB (hPRa2; Labvision Neomarkers, Fremond, CA, USA), rabbit polyclonal antibody recognizing PRA and PRB (hPgR Ab8; Neomarkers, Fremont, CA, USA), and mouse monoclonal antibody recognizing ER $\alpha$ (sc-8002; Santa Cruz Biotechnology). All experimental conditions regarding western immunoblotting were described earlier by Smid-Koopman et al. (2005).

\section{Cell proliferation experiments}

The cells were cultured for 6 days in the presence or absence of increasing concentrations of tibolone, $\mathrm{E}_{2}$ or MPA, or in the presence of $1 \mathrm{nM} E_{2}+$ increasing concentrations of MPA. The hormonal concentrations are indicated in Fig. 1. The proliferation was measured using ${ }^{3} \mathrm{H}$-thymidine incorporation as described earlier by Gielen et al. (2005).

\section{Isolation of RNA}

After maintaining the cells for 1 week in phenol red-free DMEM/F12 medium (Gibco, Invitrogen Life Technologies), containing $5 \%$ DCC-FBS, they were passaged, allowed to attach, and subsequently cultured for $1,6,12$, 24,48 , and $72 \mathrm{~h}$ in the absence (in total six control samples were generated) or presence of $\mathrm{E}_{2}(1 \mathrm{nM})$, MPA $(1 \mathrm{nM}), \mathrm{E}_{2}+$ MPA (both $\left.1 \mathrm{nM}\right)$, or tibolone $(100 \mathrm{nM})$. After removal of the medium, total RNA was isolated by lysing the cells with $3 \mathrm{M}$ lithium chloride/ $6 \mathrm{M}$ urea. Subsequently, the RNA was purified as described by Blok et al. (1995). After RNA cleanup (Qiagen), RNA levels, quality, and purity were assessed with the use of the RNA 6000 Nano assay on the Agilent 2100 Bioanalyzer (Agilent, Palo Alto, CA, USA). None of the samples showed RNA degradation or contamination by DNA.

\section{Gene profiling and quality control}

The samples were analyzed using Affymetrix U133plus2 GeneChips containing 54614 probe sets, representing approximately 47000 transcripts (30 000 genes). We used $1 \mu \mathrm{g}$ total RNA to prepare antisense biotinylated RNA according to Affymetrix protocol for gene chip experiments (Affymetrix). All GeneChips were visually inspected for irregularities. The global method of scaling or normalization was applied. All additional measures of quality indicated a high overall quality of the samples and assays. 


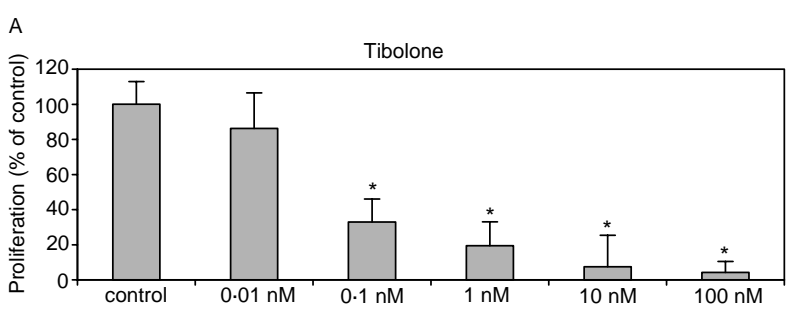

B
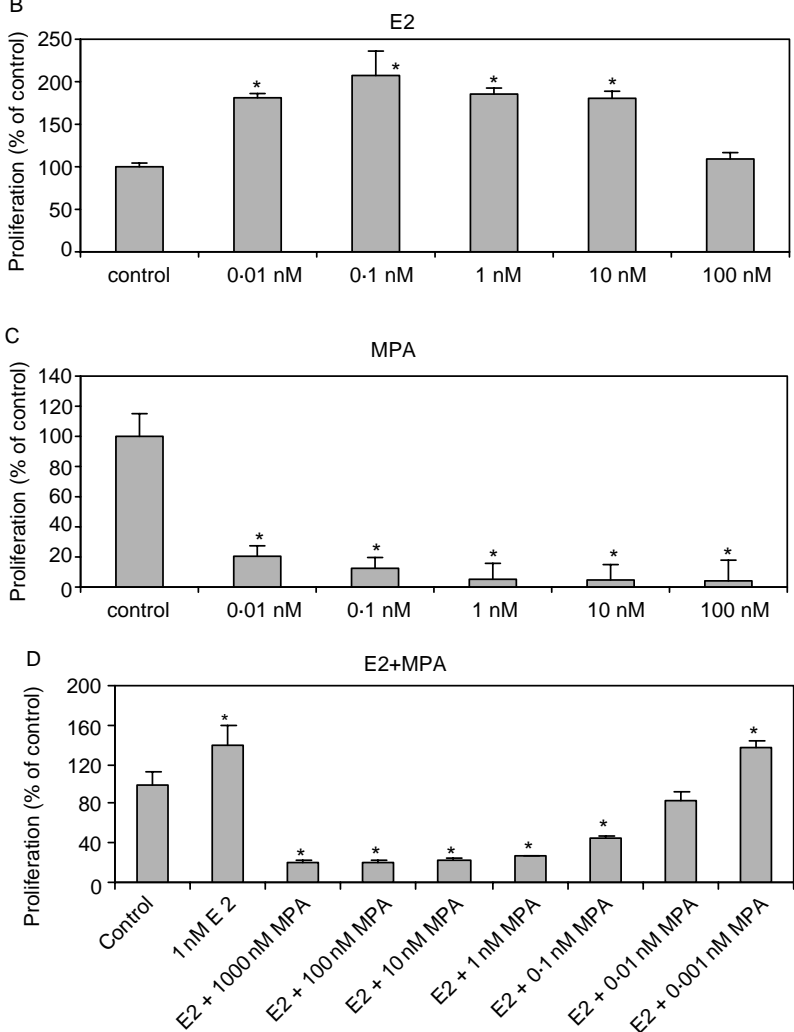

Figure 1 Effect of tibolone, $E_{2}, M P A$, or $E_{2}+$ MPA on proliferation of the ECC1-PRAB72 cell line. The cells were cultured for 6 days in the absence (control) or the presence of increasing amounts of tibolone (A) $(0 \cdot 01,0 \cdot 1,1,10,100 \mathrm{nM}), \mathrm{E}_{2}$ (B) $(0 \cdot 01,0 \cdot 1,1,10,100 \mathrm{nM})$, MPA (C) $(0.01,0 \cdot 1,1,10,100 \mathrm{nM})$, or $E_{2}(1 \mathrm{nM})+\mathrm{MPA}$ (D) $(1000,100$, $10,1,0 \cdot 1,0 \cdot 01,0 \cdot 001 \mathrm{nM})$ before ${ }^{3} \mathrm{H}$-thymidine was added overnight. The cells were subsequently washed and lysed, and the incorporation of radioactivity measured. The experiment was repeated twice and one representative experiment is shown. S.D.s of three replicate measurements are shown. Asterisk $\left(^{*}\right)$ indicates a $P$ value $<0.01$ (Student's $t$-test). The $Y$ axis represents the percentage of growth relative to control, which is set at $100 \%$.

\section{Statistical analyses}

Data normalization was done according to the quantile method (Bolstad et al. 2003). The level of expression of each probe set in every hormone-treated sample at each time-point was determined relative to its corresponding control sample and transformed logarithmically (on a base 2 scale). A threefold change deviation from the control reflects differential gene expression. Genes (probe sets) whose level of expression differed from the controls (reflecting up- or down regulation) in at least one sample were selected for further analysis. In total, 3067 out of 54614 probe sets corresponding to 2063 known and 281 unknown genes were selected for further analysis. The Omniviz package (Omniviz) was used to perform and visualize the results of unsupervised cluster analysis. The list of differentially expressed genes is available at http://www2.eur.nl/fgg/rede/ hanifi_moghaddam. Gene expression data were also analyzed using Time series regression analysis from http://linus.nci.nih.gov/brb-arraytools.html. The results from this analysis can be accessed from http:// www2.eur.nl/fgg/rede/hanifi_moghaddam.

The classification of genes into biological processes was done using GoTree Machine (http://genereg.ornl. gov/gotm) and Celera database (https://panther. appliedbiosystems.com/). In order to identify biological processes with significantly enriched or depleted gene numbers, we need to compare, for each biological process, the distribution of genes in each hormoneregulated gene list with those in the reference gene list. It should be noted that an inappropriate reference list would lead to a wrong identification of regulated biological processes. Therefore, we used two reference lists: the Affymetrix 133Uplus2 gene list and the National Center for Biotechnology Information (NCBI) human gene list (n-23520). The enrichment or depletion of genes in a certain biological process indicates hormonal regulation. The significance of enrichment or depletion for a given process is determined by the $P$ value (see references given on the websites). Those processes with $P$ values $<10^{-4}$ were considered statistically significant and modulated.

\section{Validation of array data by quantitative PCR}

The validation of microarray expression data was accomplished by quantitative real-time reverse transcriptase (RT)-PCR on nine randomly selected genes MGP, FOS, MUC1, EGR1, CTSD, KRT18L1, IGFBP4, $B C M P 11, A R E G$ and five tibolone-regulated genes PITX1, TFCP2L2, THADA, MCM2, and ID1. The experimental protocol and part of the results are available on our website (http://www2.eur.nl/fgg/ rede/hanifi_moghaddam).

\section{Results}

\section{Characterization of ECC1-PRAB72 cells}

The hormone responsiveness of the ECC1-PRAB72 cells was characterized by evaluating the effects of hormone treatments on the expression of PR and ER and the cell proliferation. Western blotting indicated that PRA, 


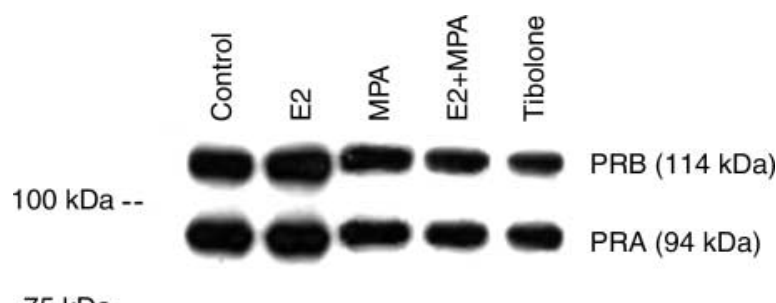

$75 \mathrm{kDa}--$

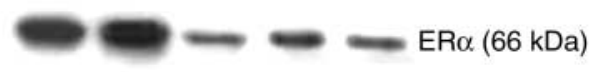

$50 \mathrm{kDa}--$

Figure 2 Effect of tibolone, $E_{2}$, MPA, or $E_{2}+$ MPA on PRA, PRB, and ER $\alpha$ expressions in the ECC1-PRAB72 cell line. The cells were cultured for $24 \mathrm{~h}$ in the absence (control) or presence of $\mathrm{E}_{2}$ (1 nM), MPA (1 nM), $E_{2}+$ MPA (1 nM), or tibolone (100 nM) before the lysates were separated on SDS-PAGE and blotted on nitrocellulose. PRA and PRB were detected using an antibody that recognized both $\mathrm{PR}$ isoforms; ER $\alpha$ was detected using an $\mathrm{ER} \alpha-$ specific antibody. Equal loading of protein was verified using Ponceau S staining of the blot. The molecular-weight marker is indicated to the left of the figure.

$\mathrm{PRB}$, and ER $\alpha$ expressions were reduced in the presence of tibolone, MPA, or $\mathrm{E}_{2}+\mathrm{MPA}$ (Fig. 2). Furthermore, the ER $\alpha$ expression was slightly increased upon culture in the presence of $\mathrm{E}_{2}$.

Cell proliferation was also clearly affected by the hormonal treatments (Fig. 1); $\mathrm{E}_{2}$-stimulated proliferation of the cells, while tibolone and MPA resulted in a pronounced inhibition of proliferation. It should be noted, however, that tibolone is required at a concentration 100 times higher to show similar inhibitory effect as MPA ( $100 \mathrm{vs} 1 \mathrm{nM})$. MPA was also able to counteract the $\mathrm{E}_{2}$-stimulated growth. Based on these results, we hypothesized that tibolone behaves much more similar to MPA and $\mathrm{E}_{2}+\mathrm{MPA}$ treatment, than to $\mathrm{E}_{2}$ treatment.

\section{Profile similarities}

In total, 2344 out of approximately 30000 genes were differentially expressed (at least threefold deviation from the control levels in one or more time-points) and were selected for further analyses (Figs 3 and 4). The expression patterns of nine randomly selected genes were confirmed by realtime RT-PCR indicating that the microarray experiment was of high quality (http://www2.eur.nl/fgg/ rede/hanifi_moghaddam; Fig. 5).

Unsupervised cluster analysis was applied to analyze profile similarity between different treatments (Fig. 3). In addition, the magnitude of profile similarity between tibolone and the other hormones is indicated in terms of the number of regulated genes for each time-point in
Fig. 4A-C. In addition, the magnitude of profile specificity for each hormone treatment in terms of the number of treatment-specific genes is indicated in Fig. 4D. Our definition of a treatment-specific gene is if a gene is only modulated by one hormonal treatment and not by any of the other hormonal treatments at any time points.

In the unsupervised cluster analysis (Fig. 3), three main clusters were defined by the software program and can be distinguished. The first main cluster contains all 1-h expression profiles of all hormonal treatments. Since the numbers of regulated genes are small, the only relevant conclusion drawn from this cluster is that at $1 \mathrm{~h}$, gene regulation by the four hormonal treatments is clearly different from that measured after longer treatment times.

Interestingly, after $1 \mathrm{~h}$, the $\mathrm{E}_{2}$ profiles are disassociated from the other profiles and form the second main cluster. On average, considering all time-points excepting $1 \mathrm{~h}$, only $7 \%$ of the total number of genes regulated by tibolone is regulated by $\mathrm{E}_{2}$ also. This result was not unexpected because the cell proliferation data indicated a clear opposite response to tibolone when compared with $\mathrm{E}_{2}$ (Fig. 1A versus $\mathrm{B}$ ).

The third main cluster is formed by the profiles generated after $6,12,24,48$, and $72 \mathrm{~h}$ of treatment of the ECC1-PRAB72 cells with tibolone, MPA, or $\mathrm{E}_{2}+$ MPA. Within this cluster, a number of sub-clusters can be defined. First, at 6 and $12 \mathrm{~h}$, the profiles of tibolone, MPA, and $\mathrm{E}_{2}+$ MPA cluster together. Second, the 24, 48, and 72-h $\mathrm{E}_{2}+\mathrm{MPA}$ treatment dissociates from the other treatments and forms its own sub-cluster. Third, at 24, 48 , and $72 \mathrm{~h}$, tibolone and MPA cluster closely together. These observations are strengthened by the percentages of the shared genes; tibolone and $\mathrm{E}_{2}+$ MPA share about $41 \%$ of regulated genes and this percentage increases to $55 \%$ for tibolone and MPA alone. Interestingly, despite these similarities, there is still a relatively large proportion of genes which is hormone treatment-specific (Fig. 4D). In total, 366 genes were exclusively regulated by tibolone, 67 genes were specifically regulated by $\mathrm{E}_{2}+\mathrm{MPA}, 269$ genes were MPAspecific, and 221 genes were $\mathrm{E}_{2}$-specific (Fig. 4D).

\section{Physiological similarities}

Cluster analysis groups genes based on their expression pattern and does not consider the functional relationships between genes. In theory, genes that are functionally unrelated could be co-regulated due to their physical vicinity on the genome and thus can be clustered together (Zhang et al. 2003). In order to understand the (dis) similarity of expression profiles in terms of biological processes, all differentially regulated genes were classified into biological processes and those 


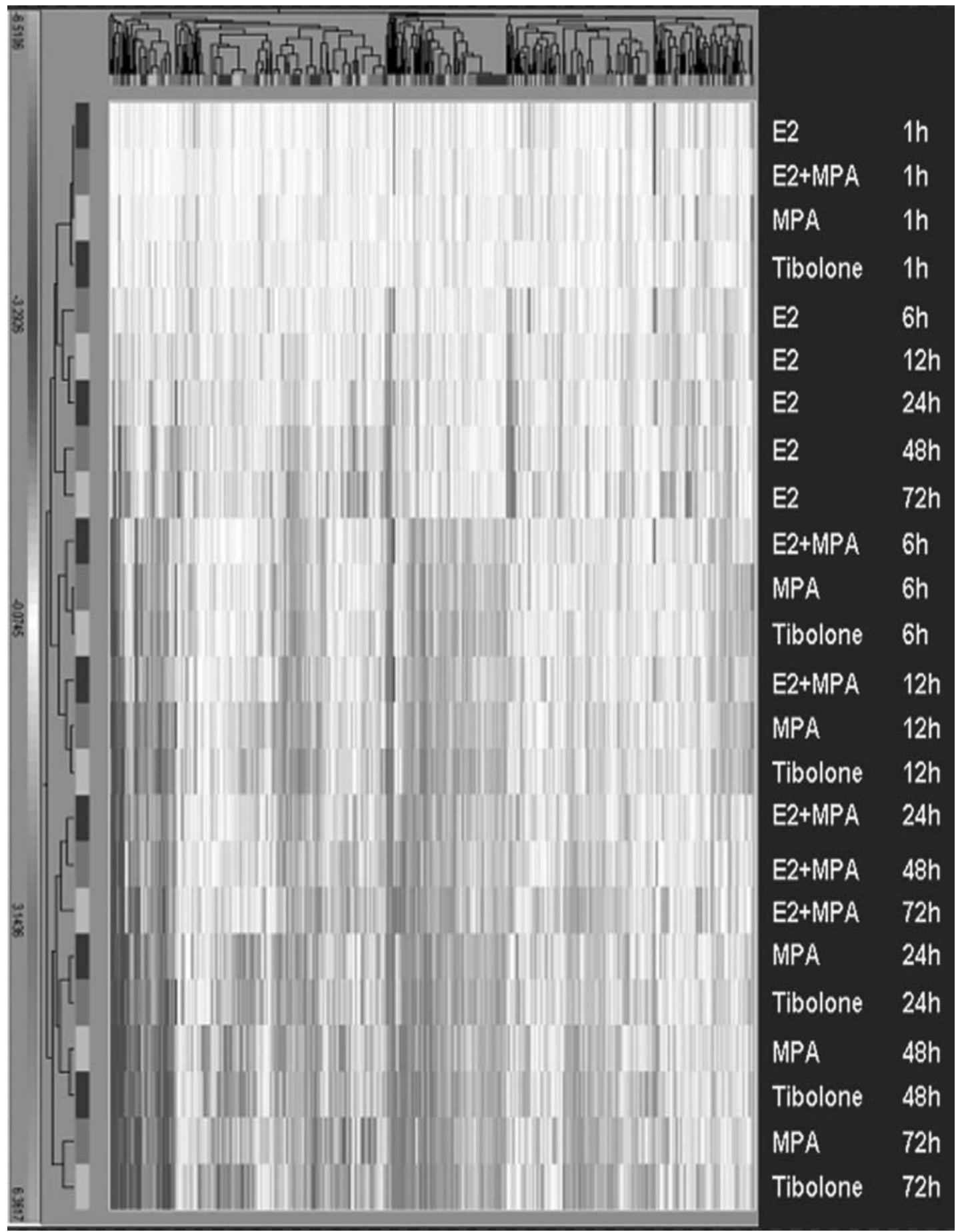

Figure 3 Effect of tibolone, $E_{2}$, MPA or $E_{2}+$ MPA on the transcription profile of the ECC1-PRAB72 cell line. The cells were cultured for $1,6,12,24,48$, or $72 \mathrm{~h}$ in the absence or presence of tibolone (100 nM), $E_{2}(1 \mathrm{nM})$, MPA (1 nM), or $E_{2}+$ MPA (both $1 \mathrm{nM}$ ) before RNA was isolated from the cells. The expression profiles were generated from all conditions and genes were considered regulated if expression differed by at least a factor 3 from control expression. In total, 2063 known and 281 unknown genes were found to be regulated by any of the treatments. The expression of those genes was analyzed relative to the expression under control conditions using unsupervised clustering. Unsupervised clustering arranges genes and treatments on the basis of calculated similarities (www.omniviz.com). The colors represent at least threefold higher expression than under control conditions (red) or threefold lower expression than the control values (blue). The intensity of the colors indicates the fold difference from control. 

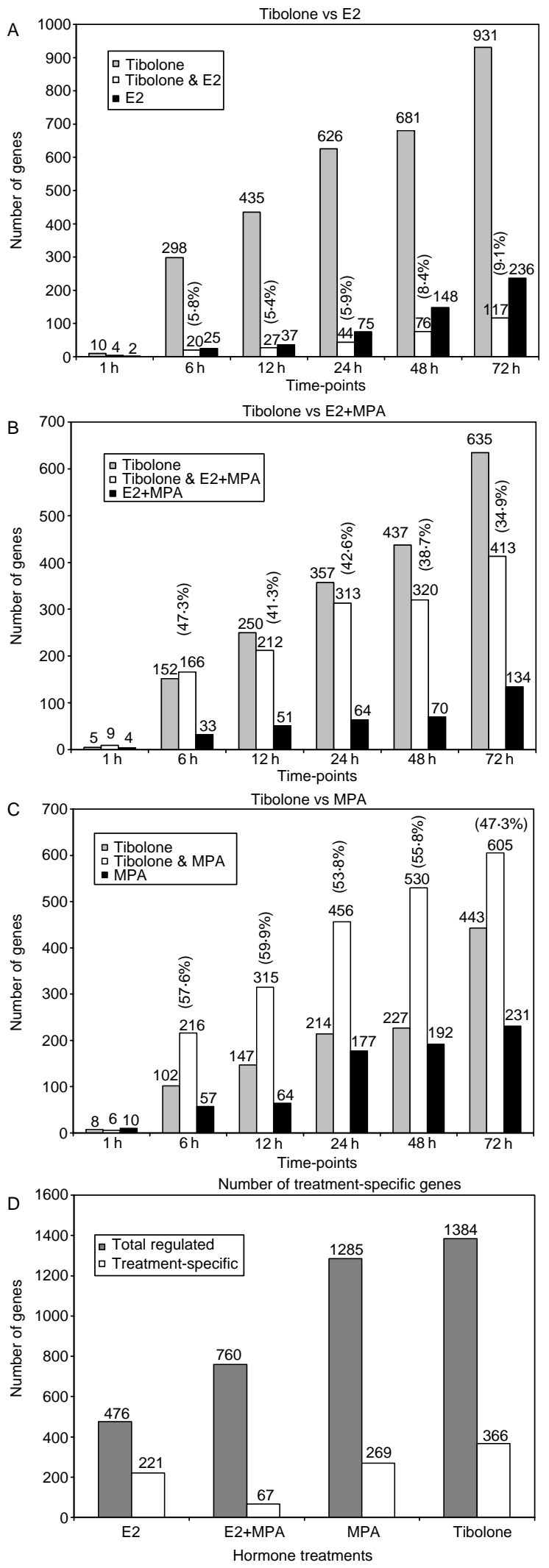

processes with significantly enriched gene numbers were identified. 'Cell growth' and 'morphogenesis' were the most significantly regulated processes by $\mathrm{E}_{2}$ and $\mathrm{E}_{2}+\mathrm{MPA}\left(P<10^{-4}\right)$. The 'cell cycle' was found to be the most significantly regulated process by tibolone and MPA treatment $\left(P<10^{-15}\right)$.

\section{Discussion}

The initial characterization of the ECC1-PRAB72 cell line shows that as far as PR/ER expression and growth regulation is concerned, tibolone resembles $\mathrm{E}_{2}+\mathrm{MPA}$ and MPA treatment. This observation is refined upon analyzing the gene expression profiles of the different treatments, which shows the highest similarity of tibolone treatment to MPA treatment. Based on these two observations, we conclude that the molecular working mechanisms of tibolone and MPA in the welldifferentiated endometrial carcinoma cell line ECC1PRAB72, are very similar. However, this conclusion oversimplifies the reality; the expression profiles of tibolone and MPA indeed clustered together, but this result is obtained only through a $55 \%$ overlap between the genes that are regulated by tibolone and MPA.

Upon administration of a hormone to a cellular system, usually some genes are transiently regulated, while others are more permanently (constitutively) regulated. It can be argued that the permanently regulated genes are generally those that are important for a sustained hormonal effect on a cellular model. Upon reviewing those genes that were regulated at least at the 24, 48, and 72-h time-points (permanently) in the present experiments, it was found that the percentages of overlapping genes between the hormonal treatments changed. It was calculated that 393 genes out of a total of 1384 tibolone-regulated genes were regulated permanently. The overlap with permanently $\mathrm{E}_{2}$-regulated

Figure 4 The overlap between tibolone-regulated genes and genes regulated by $E_{2}$, MPA, or $E_{2}+$ MPA. The total number of tibolone-regulated genes at each time-point was compared with the number of $E_{2}$-regulated genes $(A)$, with the number of $E_{2}+$ MPA-regulated genes (B), and with the number of MPA-regulated genes (C). The numbers of genes only regulated by tibolone or by the indicated treatment are shown (gray and black bars), as well as the numbers (and in parenthesis the percentage, except for $1 \mathrm{~h}$ ) of genes that were regulated by both treatments (open bars). Due to the small number of regulated genes at the 1-h time-points, the percentages of shared genes were considered unreliable. The average of the percentage of shared genes (over five timepoints) between tibolone and $E_{2}$ is $6.9 \%$, between tibolone and $E_{2}+$ MPA is $41 \%$ and between tibolone and MPA is $54.9 \%$, (D) represents the total number of regulated genes in each treatment (gray bars) and treatment-specific genes (genes that are only modulated by one hormonal treatment and not by any of the other hormonal treatments; white bars). 

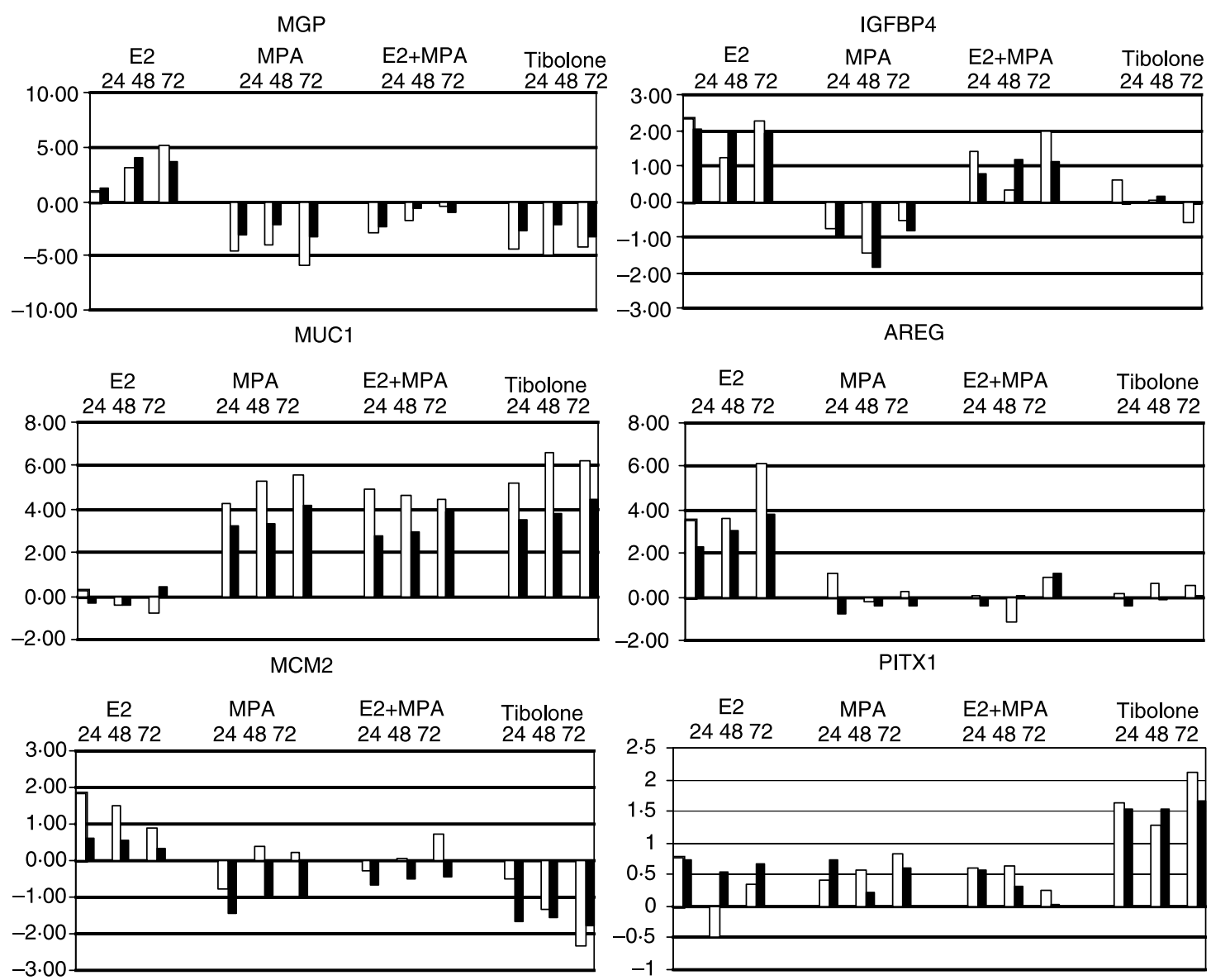

Figure 5 Validation of microarray experiments by quantitative real-time RT-PCR. Validation was accomplished on nine randomly selected genes MGP, FOS, MUC1, EGR1, CTSD, KRT18L1, IGFBP4, BCMP11, AREG and five tiboloneregulated genes PITX1, TFCP2L2, THADA, MCM2, and ID1. Here only MGP, IGFBP4, MUC1, AREG, MCM2, and PITX1 are shown. The other results are available from http://www2.eur.nl/fgg/rede/hanifi_moghaddam. The $Y$ axis represents the logarithmically transformed (on a base 2 scale) expression values relative to control values. White bars are the data from RT-PCR and black bars are the data from the microarray experiments. Treatments and time of culture is indicated at the top of each figure.

genes was only $7 \%$, with permanently $\mathrm{E}_{2}+\mathrm{MPA}-$ regulated genes was $58 \%$, and with permanently MPAregulated genes was $77 \%$. Interestingly, if these percentages are compared with the overall overlappercentages, the overlap between tibolone and $\mathrm{E}_{2}$ remained unchanged, while that between tibolone and $\mathrm{E}_{2}+\mathrm{MPA}$, and tibolone and MPA markedly increased ( $\mathrm{E}_{2}+\mathrm{MPA}: 41 \%$ becomes $58 \%$; MPA: $55 \%$ becomes $77 \%)$. Upon reviewing the permanently tibolone-regulated genes in more detail, only 21 genes were truly tibolone-specific (never regulated at any time-point by any of the other hormonal treatments). From six of these genes, no additional information was available in literature, which left 15 genes with a putative common element that links them to tibolonesignaling. A literature search indicated that most of the 15 genes could be linked to general processes like differentiation (TWSG1, TFCP2L2, SLC39A14, PITX1,
THADA, ID1) and the cell cycle (PPP3CC, MCM2, $A S F 1 B, E L L)$.

Upon reviewing the literature further, minichromosome maintenance deficient 2 (MCM2) turned out to be the most interesting because it is part of a complex, which is prerequisite for DNA replication (Bailis \& Forsburg 2004). The minichromosome maintenance proteins (MCM2-MCM7) form a heterohexamer that is part of the prereplication complex. DNA replication begins with loading of the origin recognition complex, followed by recruitment of Cdc6/Cdc45, followed by loading of the MCM2-7 complex (Guida et al. 2005). Upon entering the S-phase, Cdc6 is released and kinase activity recruited (Cdc2-cyclinE and Dbf4-Cdc7) to initiate DNA synthesis. Because the prereplication complex dissociates from DNA, replication of each region on the genome occurs only once during a cell cycle (Guida et al. 2005). In general, replicating cells 
Table 1 Genes regulated by tibolone or MPA and involved in the prereplication complex

\begin{tabular}{|c|c|c|c|c|c|c|}
\hline & \multicolumn{3}{|l|}{ MPA } & \multicolumn{3}{|c|}{ Tibolone } \\
\hline & $24 \mathrm{~h}$ & $48 \mathrm{~h}$ & $72 \mathrm{~h}$ & $24 \mathrm{~h}$ & $48 \mathrm{~h}$ & $72 \mathrm{~h}$ \\
\hline CDK6 & $-1 \cdot 04$ & $-1 \cdot 23$ & $-1 \cdot 62$ & -0.86 & $-1 \cdot 36$ & -1.56 \\
\hline CDK2 & $-2 \cdot 29$ & -0.85 & -0.73 & $-1 \cdot 21$ & -0.78 & $-1 \cdot 79$ \\
\hline CDC45L & $-1 \cdot 18$ & $-1 \cdot 24$ & -0.81 & $-1 \cdot 25$ & $-1 \cdot 34$ & $-1 \cdot 71$ \\
\hline MCM5 & $-1 \cdot 42$ & -0.84 & -0.88 & $-1 \cdot 27$ & $-1 \cdot 24$ & $-2 \cdot 18$ \\
\hline MCM4 & $-1 \cdot 72$ & -0.49 & -0.80 & -1.45 & -0.78 & $-1 \cdot 28$ \\
\hline MCM3 & $-1 \cdot 04$ & -0.69 & -0.82 & $-1 \cdot 37$ & $-1 \cdot 26$ & -1.56 \\
\hline MCM2 & -1.43 & -0.93 & -1.01 & -1.69 & -1.54 & $-1 \cdot 76$ \\
\hline
\end{tabular}

The numbers indicate the logarithmically transformed (on a base 2 scale) expression values relative to the control values (negative numbers indicate downregulated genes). The gray boxes indicate those genes that were found to be downregulated by a factor 3 or more as compared with control values. To the left, the gene titles are provided. CCNE2 represents cyclin $\mathrm{E}_{2}$, and CDC45L is the gene title for CDC45. The entire gene list can be accessed from http:// www2.eur.nl/fgg/rede/hanifi_moghaddam.

have higher levels of MCM proteins than quiescent cells. During the menstrual cycle, this finding was illustrated in a physiological setting; in the follicular (proliferative) phase, MCM2 and MCM3 levels were found to be significantly higher than during the luteal (differentiation) phase (Kato et al. 2003).

Upon analyzing our own data concerning prereplication complex-regulated genes (Table 1), it was observed that most of the above-mentioned genes were clearly downregulated by tibolone as well as MPA. Since a downregulation of components of the prereplication complex is highly correlated to downregulation of proliferation in the endometrium (Kato et al. 2003), these findings can at least partly explain the growthinhibitory properties of tibolone and MPA.

The fact that tibolone acts very similar to MPA was drawn from the results as discussed above. A question, which remains then, is where this progestagenic activity comes from. A simple explanation would be if tibolone was metabolized $100 \%$ to its progestagenic isomer $\Delta^{4}$ tibolone. This, however, is not the case. Earlier work showed that in ECC1 cells tibolone is converted at least

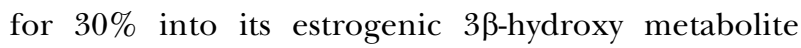
(Hanifi-Moghaddam et al. 2005). Earlier work also indicated that this amount of $3 \beta$-hydroxy tibolone is enough to provide a clear estrogen-like response in ECC1 cells (Hanifi-Moghaddam et al. 2005). It is possible that over time $3 \beta$-hydroxy tibolone is converted back into $\Delta^{4}$-tibolone (Schatz et al. 2005). However, our array data show that, like MPA, they are tibolone's own progestagenic properties which are responsible for an increased expression of the aldo-keto reductase family 1 member C1 (AKR1C1, an enzyme that catalyzes the

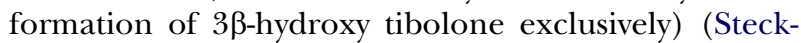
elbroeck et al. 2004).
Another explanation for tibolone's dominant progestagenic properties can be found in the first experiment that was performed to characterize the presently used cell line. In Fig. 2, it is shown that MPA, $\mathrm{E}_{2}+\mathrm{MPA}$, and tibolone treatments clearly result in a profound reduction in ER $\alpha$ expression. It is very well possible that this reduction in $\mathrm{ER} \alpha$ expression is responsible for the diminished estrogenic response that is left after tibolone treatment of the cell line.

It is also possible that tibolone's progestagenic dominance has to do with the fact that a cancer cell line was used. The presently used ECC1-PRAB72 endometrial carcinoma cell line has a relatively high proliferation rate. It is possible that due to this, estrogens are only capable of having a relatively minor growth stimulatory effect (twofold in Fig. 1), while tibolone and MPA are highly effective to induce inhibition of proliferation. The results presented in Fig. 1 and the high number of regulated genes by tibolone, MPA, and $\mathrm{E}_{2}+\mathrm{MPA}$ treatments when compared with $\mathrm{E}_{2}$ treatment, as shown in Fig. 4, seem to support this hypothesis.

Whether, in vivo, tibolone's progestagenic properties are dominant remains to be seen; Timmer \& Houwing (2002) observed that in serum of tibolone-treated patients, the $3 \alpha$ - and $3 \beta$-hydroxy metabolites are the most predominant metabolites, while the $\Delta^{4}$-isomer can only be measured until $6 \mathrm{~h}$ after administration. Our own data (Klaassens et al. 2006) on the endometrial tissues of healthy postmenopausal women indicate that relatively short-term tibolone treatment (21 days) results in some estrogen-like stimulation of the human endometrium, while it is specifically after long-term treatment that tibolone's progestagenic properties outweigh its estrogenic properties. To test 
this hypothesis, we are in the process of generating expression profiles of endometrial tissues from longterm tibolone users.

In summary, the answer to our main question regarding the similarity between $\mathrm{E}_{2}, \mathrm{MPA}, \mathrm{E}_{2}+\mathrm{MPA}$, and tibolone is that in the estrogen- and the progesterone-responsive endometrial cancer cell line ECC1-PRAB72, tibolone acts very similar to MPA and is clearly different from $\mathrm{E}_{2}$. However, there are also hormone-specific differences between tibolone and MPA.

\section{Acknowledgements}

This work was supported by N V Organon. The authors declare that there is no conflict of interest that would prejudice the impartiality of this scientific work.

\section{References}

Anderson GL, Judd HL, Kaunitz AM, Barad DH, Beresford SA, Pettinger M, Liu J, McNeeley SG, Lopez AM \& Women's Health Initiative Investigators 2003 Effects of estrogen plus progestin on gynecologic cancers and associated diagnostic procedures: the women's health initiative randomized trial. Journal of the American Medical Association 290 1739-1748.

Bailis JM \& Forsburg SL 2004 MCM proteins: DNA damage, mutagenesis and repair. Current Opinion in Genetics and Development 14 17-21.

Beral V, Bull D \& Reeves G 2005 Endometrial cancer and hormonereplacement therapy in the million women study. Lancet $\mathbf{3 6 5}$ $1543-1551$.

Blok LJ, Grossmann ME, Perry JE \& Tindall DJ 1995 Characterization of an early growth response gene, which encodes a zinc finger transcription factor, potentially involved in cell cycle regulation. Molecular Endocrinology 9 1610-1620.

Bolstad BM, Irizarry RA, Astrand M \& Speed TP 2003 A comparison of normalization methods for high density oligonucleotide array data based on variance and bias. Bioinformatics 19 185-193.

de Gooyer ME, Oppers-Tiemissen HM, Leysen D, Verheul HA \& Kloosterboer HJ 2003 Tibolone is not converted by human aromatase to 7alpha-methyl-17alpha-ethynylestradiol (7alphaMEE): analyses with sensitive bioassays for estrogens and androgens and with LC-MSMS. Steroids 68 235-243.

Gielen SC, Hanekamp EE, Blok LJ, Huikeshoven FJ \& Burger CW 2005 Steroid-modulated proliferation of human endometrial carcinoma cell lines: any role for insulin-like growth factor signaling? Journal of the Society for Gynecologic Investigation 12 58-64.

Guida T, Salvatore G, Faviana P, Giannini R, Garcia-Rostan G, Provitera L, Basolo F, Fusco A, Carlomagno F \& Santoro M 2005 Mitogenic effects of the up-regulation of minichromosome maintenance proteins in anaplastic thyroid carcinoma. Journal of Clinical Endocrinology and Metabolism 90 4703-4709.

Hanifi-Moghaddam P, Gielen SC, Kloosterboer HJ, De Gooyer ME, Sijbers AM, van Gool AJ, Smid M, Moorhouse M, van Wijk FH, Burger CW et al. 2005 Molecular portrait of the progestagenic and estrogenic actions of tibolone: behavior of cellular networks in response to tibolone. Journal of Clinical Endocrinology and Metabolism 90 973-983.

Kato K, Toki T, Shimizu M, Shiozawa T, Fujii S, Nikaido T \& Konishi I 2003 Expression of replication-licensing factors MCM2 and MCM3 in normal, hyperplastic, and carcinomatous endometrium: correlation with expression of Ki-67 and estrogen and progesterone receptors. International Journal of Gynecological Pathology 22 334-340.

Klaassens AHA, Van Wijk FH, Hanifi-Moghaddam P, Sijmons B, Ewing PC, Ten Kate-Booij MJ, Kooi GS, Kloosterboer HJ, Blok LJ \& Burger CW 2006 Histological and immunohistochemical evaluation of postmenopausal endometrium after 3 weeks of treatment with tibolone, estrogen-only, or estrogen plus progestagen. Fertility and Sterility 86 352-361.

Kloosterboer HJ 2001 Tibolone: a steroid with a tissue-specific mode of action. Journal of Steroid Biochemistry and Molecular Biology 76 231-238.

Markiewicz L \& Gurpide E 1990 In vitro evaluation of estrogenic, estrogen antagonistic and progestagenic effects of a steroidal drug (Org OD-14) and its metabolites on human endometrium. Journal of Steroid Biochemistry and Molecular Biology 35 535-541.

Satyaswaroop PG, Zaino RJ \& Mortel R 1983 Human endometrial adenocarcinoma transplanted into nude mice: growth regulation by estradiol. Science 219 58-60.

Schatz F, Kuczynski E, Kloosterboer HJ, Buchwalder L, Tang C, Krikun G \& Lockwood CJ 2005 Tibolone and its metabolites enhance tissue factor and PAI-1 expression in human endometrial stromal cells: evidence of progestagenic effects. Steroids 70 840-845.

Smid-Koopman E, Kuhne LC, Hanekamp EE, Gielen SC, De Ruiter PE, Grootegoed JA, Helmerhorst TJ, Burger CW, Brinkmann AO, Huikeshoven FJ et al. 2005 Progesterone-induced inhibition of growth and differential regulation of gene expression in PRA- and/or PRBexpressing endometrial cancer cell lines. Journal of the Society for Gynecologic Investigation 12 285-292.

Steckelbroeck S, Jin Y, Oyesanmi B, Kloosterboer HJ \& Penning TM 2004 Tibolone is metabolized by the 3alpha/3betahydroxysteroid dehydrogenase activities of the four human isozymes of the aldo-keto reductase $1 \mathrm{C}$ subfamily: inversion of stereospecificity with a delta5(10)-3-ketosteroid. Molecular Pharmacology 66 1702-1711.

Tang B, Markiewicz L, Kloosterboer HJ \& Gurpide E 1993 Human endometrial 3 beta-hydroxysteroid dehydrogenase/isomerase can locally reduce intrinsic estrogenic/progestagenic activity ratios of a steroidal drug (Org OD 14). Journal of Steroid Biochemistry and Molecular Biology 45 345-351.

Taylor AH \& Al-Azzawi F 2000 Immunolocalisation of oestrogen receptor beta in human tissues. Journal of Molecular Endocrinology 24 $145-155$.

Timmer CJ \& Houwing NS 2002 Dose proportionality of three different doses of tibolone. Pharmacotherapy 226.

Tseng L \& Gurpide E 1975 Induction of human endometrial estradiol dehydrogenase by progestins. Endocrinology 97 825-833.

Zhang H, Pan KH \& Cohen SN 2003 Senescence-specific gene expression fingerprints reveal cell-type-dependent physical clustering of up-regulated chromosomal loci. PNAS $\mathbf{1 0 0}$ $3251-3256$

Received 31 May 2006

Accepted 10 August 2006

Made available online as an Accepted Preprint 12 October 2006 